Vicente Bernaschina Schürmann y Marco Thomas Bosshard, Introducción: Orientaciones transandinas para los estudios andinos .......

\title{
I. TEORÍAS Y METÁFORAS
}

Pablo Valdivia Orozco, Configuración y constelación: Algunas reflexiones sobre el potencial de unos estudios transandinos ......................

Ulises Juan Zevallos Aguilar, Archipiélagos transandinos: Hacia una nueva cartografía de la transformación cultural ........................ . Marco Thomas Bosshard, Hacia una (poética de la) relación transandina: De archipiélagos caribeños y andinos o Édouard Glissant vs. John V.

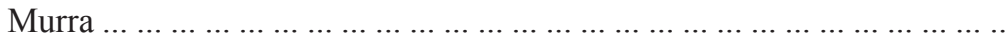

\section{LECTURAS TRANSANDINAS A TRAVÉS DE LOS SIGLOS}

Elizabeth Monasterios Pérez, Revisionismos inesperados: La contramarcha vanguardista de Gamaliel Churata y Arturo Borda .......... . Helena Usandizaga, Ejes chamánicos transandinos: Una lectura de El pez de oro, de Gamaliel Churata .......................................

MeritXell Hernando Marsal, Tramas transandinas: Dinámicas culturales

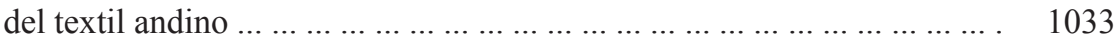

Jorge Coronado, El huayno en la ciudad: La música andina en El Sexto ... 1051

Dieter Ingenschay, De Bolivia a Buenos Aires y del premio al plagio: Migración y novela en la obra de 'Bruno Morales'

Roger Friedlein, El vuelo mágico por los Andes en El Bernardo de Bernardo de Balbuena entre dos funcionalidades 
Vicente Bernaschina Schürmann, Estelas virreinales para una configuración transandina: Las lenguas del imperio en fray Miguel de Montalvo y Enrique Garcés

\section{CODA}

OtTMar Ette, Estudios transareales y estudios transandinos

\section{RESEÑAS}

Damaris Punales-Alpizar sobre Jacqueline Loss, Dreaming in Russian. The Cuban Soviet Imaginary .......................................
Martina Bortignon sobre Magda Sepúlveda, Ciudad quiltra. Poesía chilena (1973-2013)

Margarita Vargas sobre Andrea H. Reyes, Recuerdo, recordemos: ética y política en Rosario Castellanos

Áurea María Sotomayor sobre Jean Franco, Cruel Modernity

FrAns WeISER sobre Robert Patrick Newcomb, Nossa and Nuestra América: Inter-American Dialogues .........................................

Dafne Duchesne Sotomayor sobre Jorge Olivares, Becoming Reinaldo Arenas: Family, Sexuality, and the Cuban Revolution 